\title{
Identification and Semisynthesis of (-)-Anisomelic Acid as an Oral Antiviral Agent against SARS-CoV-2 in Mice
}

\author{
Hai-Xin Yu, ${ }^{1}$ Nan Zheng, ${ }^{1}$ Chi-Tai Yeh, ${ }^{2}$ Chien-Ming Lee, ${ }^{3}$ Qi Zhang, ${ }^{4}$ Wen-Lv Zheng, ${ }^{1}$ Qing \\ Chang, ${ }^{5}$ Yuan-He Li, ${ }^{6}$ Gui-Zhen Wu, ${ }^{7 *}$ Jun-Min Quan, ${ }^{*}$ Lin-Qi Zhang, ${ }^{4 *}$ Yew-Min Tzeng,, $8^{*}$ \\ Zhen Yang ${ }^{1,6.9^{*}}$
}

\footnotetext{
${ }^{1}$ Laboratory of Chemical Genomics, School of Chemical Biology and Biotechnology, Peking University Shenzhen Graduate School, Shenzhen, 518055, China.

${ }^{2}$ Department of Medicinal Research and Education, Taipei Medical University-Shuang Ho Hospital, New Taipei City, 23561, Taiwan.

${ }^{3}$ Department of Applied Science, National Taitung University, Taitung, 95092, Taiwan.

${ }^{4}$ Center for Global Health and Infectious Diseases, Comprehensive AIDS Research Center, and Beijing Advanced Innovation Center for Structural Biology, School of Medicine, Tsinghua University, Beijing, 100084, China.

${ }^{5}$ Lanzhou Institute of Separation Science, 451 Yannan Road, Chengguan District, Lanzhou, Gansu Province, 730013, China.

${ }^{6}$ State Key Laboratory of Bioorganic Chemistry and Molecular Engineering of Ministry of Education and Beijing National Laboratory for Molecular Science (BNLMS), College of Chemistry and Molecular Engineering, Peking University, Beijing, 100871, China.

${ }^{7}$ NHC Key Laboratory of Biosafety, National Institute for Viral Disease Control and Prevention, Chinese Center for Disease Control and Prevention, Beijing, 102206, China.

${ }^{8}$ Department of Applied Chemistry, Chaoyang University of Technology, Taichung, 41349, Taiwan.

${ }^{9}$ Shenzhen Bay Laboratory, Shenzhen, 518055, China.
}

*Corresponding author. Email: zyang@pku.edu.cn; ymtzeng@nttu.edu.tw; zhanglinqi@mail.tsinghua.edu.cn; quanjm@pku.edu.cn,wugz@ivdc.chinacdc.cn

One Sentence Summary: The natural product (-)-anisomelic acid has been identified as an orally available antiviral agent against SARS-CoV-2.

Abstract: (-)-Anisomelic acid (AA), isolated from Anisomeles indica (L.) Kuntze (Labiatae) leaves, is a macrocyclic cembranolide with a trans-fused $\alpha$-methylene- $\gamma$-lactone motif. Cytopathic effect assays showed that the anti-SARS-CoV-2 effect of AA $\left(\mathrm{IC}_{50}=4.3 \mu \mathrm{M}\right)$ is comparable to that of remdesivir $\left(\mathrm{IC}_{50}\right.$ $=2.1 \mu \mathrm{M})$, and more potent than that of molnupiravir $\left(\mathrm{IC}_{50}=27.8 \mu \mathrm{M}\right)$. Challenge studies in SARS-CoV2-infected K18-hACE2 mice showed that oral administration of AA and remdesivir can both reduce the viral titers in the lung tissue at the same level. To facilitate drug discovery, we used a semisynthetic approach to shorten the project timelines. The enantioselective semisynthesis of AA from the naturally enriched and commercially available starting material $(+)$-costunolide was achieved in five steps with a $27 \%$ 
overall yield. The developed chemistry provides opportunities for developing AA-based novel ligands for selectively targeting proteins involved in viral infection.

\section{Main Text:}

The pandemic of coronavirus disease 2019 (COVID-19) poses serious threats to global public health and places severe economic strains on the world's economy (1). Effective vaccines against COVID-19 can offer a long-term control strategy, but the ability of SARS-CoV-2 mutations to escape acquired immunity is a growing cause for concern (2). Small-molecule-based antiviral agents (3) can help to address the global threat of COVID-19. These agents, which can be easily distributed to patients and rapidly manufactured from simple and readily available commodity reagents, have a low tendency to induce drug-resistant mutations. Various drug candidates have been evaluated as treatment options (4), and remdesivir $(5,6)$ and molnupiravir (7) have been approved. The identification of broadly effective antivirals with favorable benefit/risk profiles would address the serious need for the treatment of the diseases caused by pathogenic CoVs.

Natural products have been spotlighted as potential sources of new leads for the development of therapeutic agents $(8)$ because of their unparalleled structural diversity and complexity. Anisomeles indica (L.) Kuntze (Labiatae) is found throughout the southern and tropical regions of Asia. In traditional Chinese medicine, Anisomeles indica (L.) is commonly known as "yu-chen-tsao" or "fang-feng-cao". The dried whole Anisomeles indica plant has traditionally been used for the treatment of inflammation (9), pain (10), and influenza (11).

In the early stages of the virus outbreak in 2020, we were inspired by the traditional use of Anisomeles indica in the treatment of infectious disease to identify the active ingredients in this herbal medicine and investigate their use in the treatment of COVID-19. Cytopathic effect (CPE) assay showed that $(-)$-anisomelic acid and (+)-ovatodiolide (1 and 2, Fig. 1A) have anti-SARS-CoV-2 activities, with potencies of $\mathrm{IC}_{50}=4.3 \mu \mathrm{M}$ and $\mathrm{IC}_{50}=3.0 \mu \mathrm{M}$, respectively. These potencies are comparable to that of remdesivir $\left(\mathrm{IC}_{50}=2.1 \mu \mathrm{M}\right)$, and more potent than that of molnupiravir $\left(\mathrm{IC}_{50}=27.8 \mu \mathrm{M}\right)$. In addition, challenge studies in a K18-hACE2 mouse model of SARS-CoV-2 showed that the reduction of viral titers by $\mathbf{1}$ and $\mathbf{2}$ were comparable to that by remdesivir in oral administration experiments. This indicates that $\mathbf{1}$ and $\mathbf{2}$ could be potential lead compounds for the development of antiviral agents.

Structurally, 1 and $\mathbf{2}$ belong to a class of naturally occurring macrocyclic cembranolides (12), and share a basic structure that consists of a 14-membered macrocyclic core with three trisubstituted olefins and a trans-fused $\alpha$-methylene- $\gamma$-lactone. The only difference between these two compounds is that the carboxyl motif in $\mathbf{1}$ is a lactone in $\mathbf{2}$. In 1975, $\mathbf{1}$ and $\mathbf{2}$ were isolated from a different plant, i.e., Anisomeles Malabarica, and identified (13), but their biological activities were not evaluated at that time. 
The majority of currently reported antiviral agents are derivatives of nucleic acid and amino acid, derived from the substrates of viral enzymes (4), therefore the development of antiviral agents based on the core structures of $\mathbf{1}$ and $\mathbf{2}$ could afford an alternative scaffold for antiviral drug discovery. Although compound 1 can be extracted from the plant Artemisia annua, it only consists of less than $0.02 \% \mathrm{~m} / \mathrm{m}$ of the plant biomass. The supplies of plant-derived $\mathbf{1}$ are unstable and inadequate for future drug development. Given the potential demand for $\mathbf{1}$, the development of a short and sustainable synthesis from simple raw material, which would minimize the time needed for its manufacture and supply, is important.

A

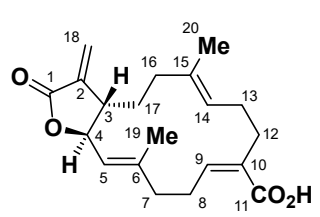

(-)-anisomelic acid (1)

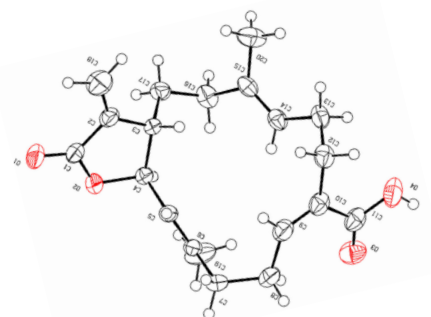

ORTEP of 1

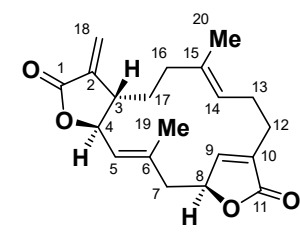

(+)-ovatodiollide (2)

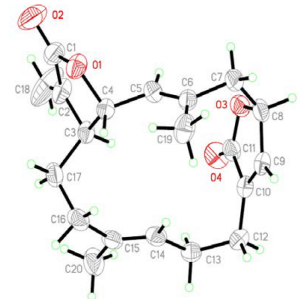

ORTEP of 2

B

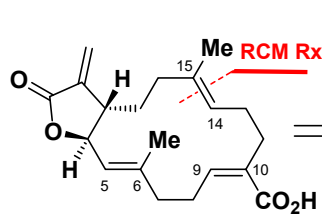

(-)-anisomelic acid (1)

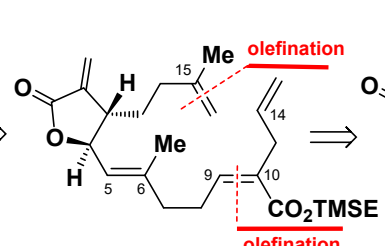

3

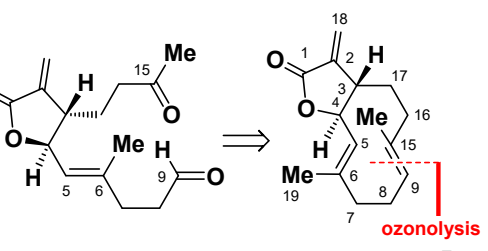

4

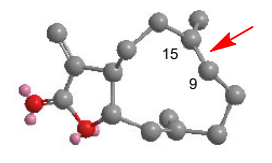

(+)-costunolide (5) optimized structure of $\mathbf{5}$

C

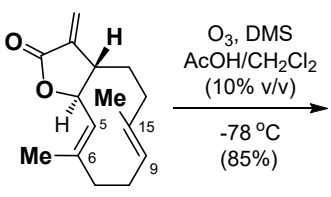

(+)-costunolide (5)

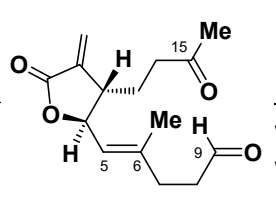

4 $\mathrm{PhO}_{\mathrm{O}}^{\mathrm{PhO}}$

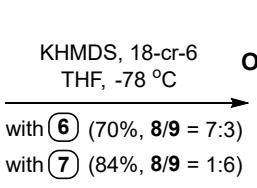

(7) $(84 \%, \mathbf{8} / \mathbf{9}=1: 6)$

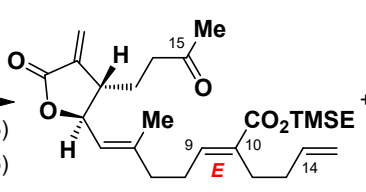

8
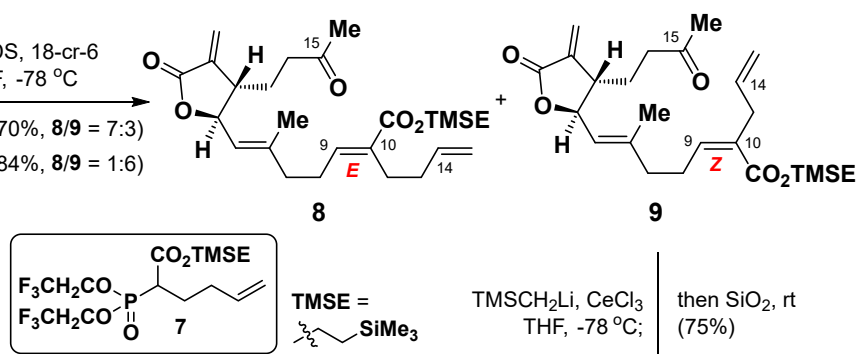

है $\mathrm{SiMe}_{3}$

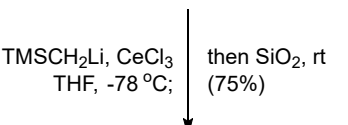

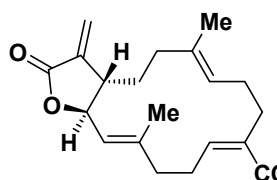

(-)-anisomelic acid (1)

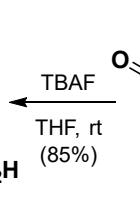

\footnotetext{
$+2$
}

Figure 1: Semisynthesis of (-)-anisomeric

Figure 1: Semisynthesis of (-)-anisomeric acid (1). (A) The structures and ORTEPs diagrams of (-)-anisomelic acid (1) and dimethyl sulfide; TMSE: trimethylsilylethyl.

The total synthesis of germacranolides has been the focus of intense research for decades, but only a few approaches to the synthesis of racemic germacranolides have been published (14). In 1987, Marshall's 
group reported the total synthesis of (-)-anisomelic acid in racemic form. The synthesis requires 21 steps, and the overall yield is ca. 1\% (15). Structurally, (-)-anisomelic acid (1) has a unique 5/14 bicyclic ring system featuring a trans-fused $\alpha$-methylene- $\gamma$-lactone moiety. This type of lactone motif is present in naturally enriched and renewable germacranolides (16), therefore we decided to develop a semisynthetic approach to preparing optically pure $\mathbf{1}$ from naturally occurring germacranolides.

In this context, $(+)$-costunolide (Fig. 1B, 5) attracted our attention because it has a trans-fused $\alpha$-methylene- $\gamma$-lactone motif, and has frequently been used as a starting material for the semisynthesis of biologically important molecules. Fig. 1B shows our retrosynthetic analysis. The macrocyclic core in the target molecule $\mathbf{1}$ can be formed regioselectively from diene $\mathbf{3}$ via Grubbs's (17) ring-closing metathesis (RCM) reaction as the key step. The diene $\mathbf{3}$ can be generated via consecutive olefinations from ketoaldehyde 4, which can be synthesized from $(+)$-costunolide (5) via a regioselective ozonolysis reaction. Although the proposed regioselective ozonolysis is challenging, we envisaged that the electron-rich nature (18) of the $\mathrm{C} 9=\mathrm{C} 15$ double bond in $\mathbf{5}$ would improve its accessibility to ozone (see the 3D structure of $\mathbf{5}$ in Fig. 1B), which would make this reaction feasible. The built-in chirality in (+)-costunolide (5) could be converted into 1 to achieve a chiral pool strategy (19), which would enable the construction of (+)ovatodiolide from the same chiral compound.

Our synthesis began with the preparation of ketoaldehyde $\mathbf{4}$ from (+)-costunolide (5) via ozonolysis (Fig. 1C). Initial attempts to achieve ozonolysis of 5 failed to afford $\mathbf{4}$, and serious decomposition was observed. However, when the reaction was performed at $-78{ }^{\circ} \mathrm{C}$ in $\mathrm{CH}_{2} \mathrm{Cl}_{2}$ with acetic acid $(10 \%)$ as a cosolvent, 4 was obtained in $85 \%$ yield. We then moved on to the synthesis of ketone 9. Initially, a HonerWadsworth-Emmons reaction of 4 with $\mathbf{6}$ in the presence of KHMDS and 18-crown-6 ether (18-C-6) gave the more stable (20) $(E)$-olefin 8 as the major isomer in $49 \%$ yield, together with 9 as a minor isomer (21\%). To improve the selectivity profile, we prepared Still Gennari electrophilic reagent 7 (21), and reacted it with 4 in the presence of KHMDS and 18-crown-6 ether; $(Z)$-olefin 9 was the predominant product (72\% yield), and $\mathbf{8}$ was formed in $12 \%$ yield.

The synthesis of diene $\mathbf{3}$ by various standard methods such as the Wittig reaction and Tebbe reaction were investigated, but synthetically useful yields of $\mathbf{3}$ were not obtained. Application of a modified Peterson olefination reaction (22) solved this problem, and diene 3 was obtained in 75\% yield when ketone 9 was reacted with excess $\mathrm{LiCH}_{2} \mathrm{Si}\left(\mathrm{CH}_{3}\right)_{3} / \mathrm{CeCl}_{3}$ with the subsequent silica gel mediated elimination. We then evaluated the feasibility of macrocyclic ring formation via the proposed RCM reaction (Fig. 1C). Several RCM reagents were profiled. In the presence of the Hoveyda-Grubbs II catalyst, the desired annulation proceeded smoothly under the optimal conditions, i.e., $0.03 \mathrm{M}$ diene 3 in $\mathrm{CH}_{2} \mathrm{Cl}_{2}$ with 0.05 equiv. of the catalyst. This method gave compounds $\mathbf{1 0}$ and $\mathbf{1 1}$ in a combined yield of $83 \%$ at a 10:11 ratio of 1:5. Conventional treatment of $\mathbf{1 1}$ with TBAF in THF at room temperature gave $\mathbf{1}$ in $85 \%$ yield. The NMR 
spectroscopic data and optical rotation of $\mathbf{1}$ were consistent with the data reported for natural (-)-anisomelic acid; the identity of $\mathbf{1}$ was unambiguously confirmed by single-crystal X-ray analysis. We therefore achieved, for the first time, an enantioselective semisynthesis of (-)-anisomelic acid(1) from (+)costunolide (5) in five steps in a $27 \%$ overall yield.

Our successful synthesis of (-)-anisomelic acid (1) encouraged us to explore the therapeutic potential of $\mathbf{1}$ and (+)-ovatodiolide (2) for the treatment of COVID-19. We first tested their abilities to inhibit SARSCoV-2 infection by using a previously established SARS-CoV-2 pseudovirus neutralization assay (23). Both (-)-anisomelic acid and (+)-ovatodiolide showed moderate anti-SARS-CoV-2 activities, with $\mathrm{IC}_{50}$ values of 20.3 and $12.4 \mu \mathrm{M}$, respectively. Their cytotoxicity in Vero E6 cells was examined in parallel with

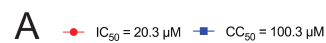
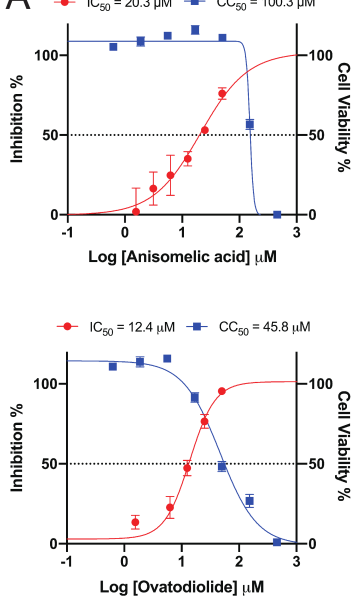

10

0 neutralization of viral infection.
B
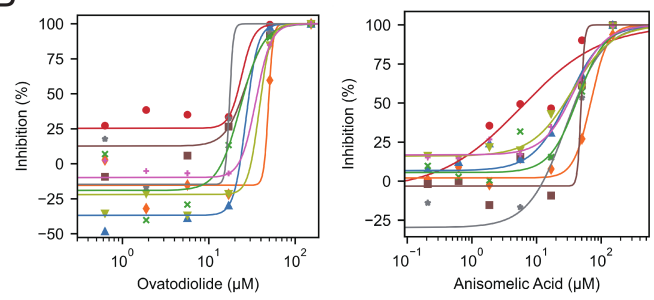

\begin{tabular}{ccc}
\hline \multirow{2}{*}{ SARS-CoV-2 Variants } & \multicolumn{2}{c}{$\mathrm{IC}_{50}(\mu \mathrm{M})$} \\
\cline { 2 - 3 } & Ovatodiolide & Anisomelic Acid \\
\hline WT & 23.9 & 5.8 \\
South Africa B.1.351 & 48.9 & 69.3 \\
Brazil P.1 & 26.9 & 48.9 \\
India B.1.617.1 & 26.8 & 31.2 \\
Uganda A23.1 & 17.2 & 28.6 \\
Nigeria B.1.525 & 23.1 & 43.3 \\
California B.1.429 & 38.2 & 35.8 \\
New York B.1.526 & 35.0 & 38.7 \\
\hline
\end{tabular}

C

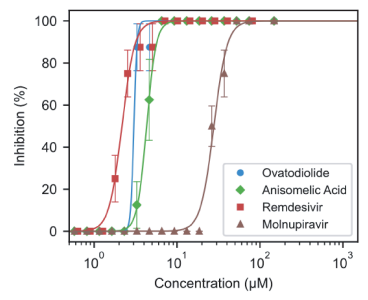

\begin{tabular}{cc}
\hline Compound & $\mathrm{IC}_{50}(\mu \mathrm{M})$ \\
\hline Ovatodiolide & $3.0(2.2-4.1)$ \\
Anisomelic acid & $4.3(4.1-4.5)$ \\
Remdesivir & $2.1(2.0-2.3)$ \\
Molnupiravir & $27.8(26.2-29.5)$ \\
\hline
\end{tabular}

Figure 2. Antiviral activities of (+)-ovatodiolide and (-)-anisomelic acid against SARS-CoV-2 in vitro. (A) Concentrationresponse relationships (red) of (-)-anisomelic acid and (+)-ovatodiolide. HeLa-hACE2 cells were treated with compounds at indicated doses and infected with the reporter SARS-CoV-2 pseudotyped virus for $48 \mathrm{~h}$. The titer percentage was determined by Gaussia luciferase luminescence flash assay. Cytotoxicity (blue) was determined using CCK-8 test. Data were expressed as mean \pm SD of three independent experiments. (B) (+)-Ovatodiolide and (-)-anisomelic acid inhibit different SARS-CoV-2 variants. Concentration-response analysis of (+)-ovatodiolide and (-)-anisomelic acid, and calculated $\mathrm{IC}_{50}$ values measured by pseudovirus neutralization assay. The results presented are representatives of two independent experiments. (C) Live SARS-CoV-2 virus neutralization assay. Neutralization activity against live prototype SARS-CoV-2 virus F13 strain was performed in a BSL-3 laboratory of the National Institute for Viral Disease Control and Prevention, China CDC. The test compound was serially diluted and mixed with an equal volume of 100 TCID50 live SARS-CoV-2 viruses. After incubation at $37{ }^{\circ} \mathrm{C}$ for $2 \mathrm{~h}$, the compound and virus mixture was added to the well of the plate containing Vero cells at a density of $2 \times 10^{5}$ per $\mathrm{mL}$; culturing was continued at 37 ${ }^{\circ} \mathrm{C}$ for 4 days. Cell and virus controls were also included. Inhibition was measured as the reciprocal of the serum dilution for $50 \%$

their antiviral activities. The $\mathrm{CC}_{50}$ of (-)-anisomelic acid is $100.3 \mu \mathrm{M}$; (+)-ovatodiolide had higher cytotoxicity, with a $\mathrm{CC}_{50}$ value of $45.8 \mu \mathrm{M}$ (Fig. 2A). Because of their increased transmissibility and 
virulence, and the possibility of decreased effectiveness toward diagnostics, vaccines, and therapeutics, newly emerged SARS-CoV-2 mutant variants pose a potential threat to public health. We therefore used pseudovirus neutralization assays (24) to assess the antiviral activities of $\mathbf{1}$ and $\mathbf{2}$ against different SARS$\mathrm{CoV}-2$ variants. Both compounds showed significant antiviral potencies against diverse SARS-CoV-2 variants, with $\mathrm{IC}_{50}$ values ranging from 5.8 to $69.3 \mu \mathrm{M}$ (Fig. 2B).

We assessed the inhibitory activities of both natural products against the CPE of the SARS-CoV-2 virus F13 strain on Vero E6 cells (25); remdesivir and molnupiravir were used as a positive control. Livevirus assays were performed in a BSL-3 laboratory at the National Institute for Viral Disease Control and Prevention, China CDC. The results indicated that (-)-anisomelic acid and (+)-ovatodiolide both show low micromolar activities, with $\mathrm{IC}_{50}$ values of $4.3 \mu \mathrm{M}$ and $3.0 \mu \mathrm{M}$, respectively. Remdesivir showed a comparable potency, with an $\mathrm{IC}_{50}$ of $2.1 \mu \mathrm{M}$; this is in agreement with the previously reported value (26); whereas molnupiravir exhibited much lower potency; with an $\mathrm{IC}_{50}$ of $27.8 \mu \mathrm{M}$ (Fig. 2C). We observed that (-)-anisomelic acid showed higher potency against cell-culture-grown SARS-CoV-2 than against the pseudovirus. This indicates that (-)-anisomelic acid may target both the entry process and other infection processes.

We next examined the ability of (-)-anisomelic acid to inhibit potential targets in the viral infection cycle. The pseudovirus assay separates the viral entry from other steps of the viral infection cycle (27); the data presented above indicate that (-)-anisomelic acid may interfere with the entry process (Fig. 2A and 2B). The SARS-Cov-2 entry process involves several steps, namely receptor binding, proteolytic processing of the spike protein, and membrane fusion (28). We first tested the inhibitory effect of (-)-anisomelic acid against the binding of the viral spike protein with neuropilin-1 (NRP1), a key host factor that mediates viral entry $(29,30)$. (-)-Anisomelic acid inhibition of binding of the viral spike protein with NRP1 in dose-dependent $\left(\mathrm{EC}_{50}=26.7 \mu \mathrm{M}\right.$; Fig. 3A-C), which is in parallel to the inhibitory effect of (-)-anisomelic acid against viral spike protein binding to the NRP1-positive (NRP1+) Huh7 cell line. This highlights the potential role of NRP1 in the viral entry process. We evaluated the effect of (-)-anisomelic acid on the activity of enzymes that are possibly involved in the proteolytic processing of the viral spike protein $(31,32)$. We found that $(-)$-anisomelic acid potently inhibited the surface protease TMPRSS2 and lysosomal proteases cathepsin $\mathrm{L}$ and $\mathrm{B}$ with $\mathrm{IC}_{50}$ values of $6.51,3.69$, and $4.23 \mu \mathrm{M}$, respectively (Fig. 3DF). These results indicated that (-)-anisomelic acid inhibits the entry process by blocking both receptor binding and proteolytic processing. Given that (-)-anisomelic acid inhibited the activities of the cysteine proteases cathepsin $\mathrm{L}$ and $\mathrm{B}$, it is likely that it also inhibits the SARS-Cov-2 main protease (3CL pro), which is the pivotal viral cysteine protease for viral replication (33). To test this, we determined the inhibitory effect of (-)-anisomelic acid on $3 \mathrm{CL}$ pro; the $\mathrm{IC}_{50}$ value is $9.77 \mu \mathrm{M}$ (Fig. 3G). These results show 
that (-)-anisomelic acid inhibited SARS-Cov-2 infection through multiple targets. Multitargeting or polypharmacology is not uncommon for natural products, which have been used for thousands of years in traditional medicine $(34,35)$. In particular, multitargeting has advantages over single-targeting, e.g., better efficacy, reduced toxicity, and, more importantly, the ability to prevent the development of resistant viral strains and to enable the treatment of viral coinfections, e.g., in combination therapies in HIV and hepatitis $\mathrm{C}$ virus (HCV) viral infections $(36,37)$.
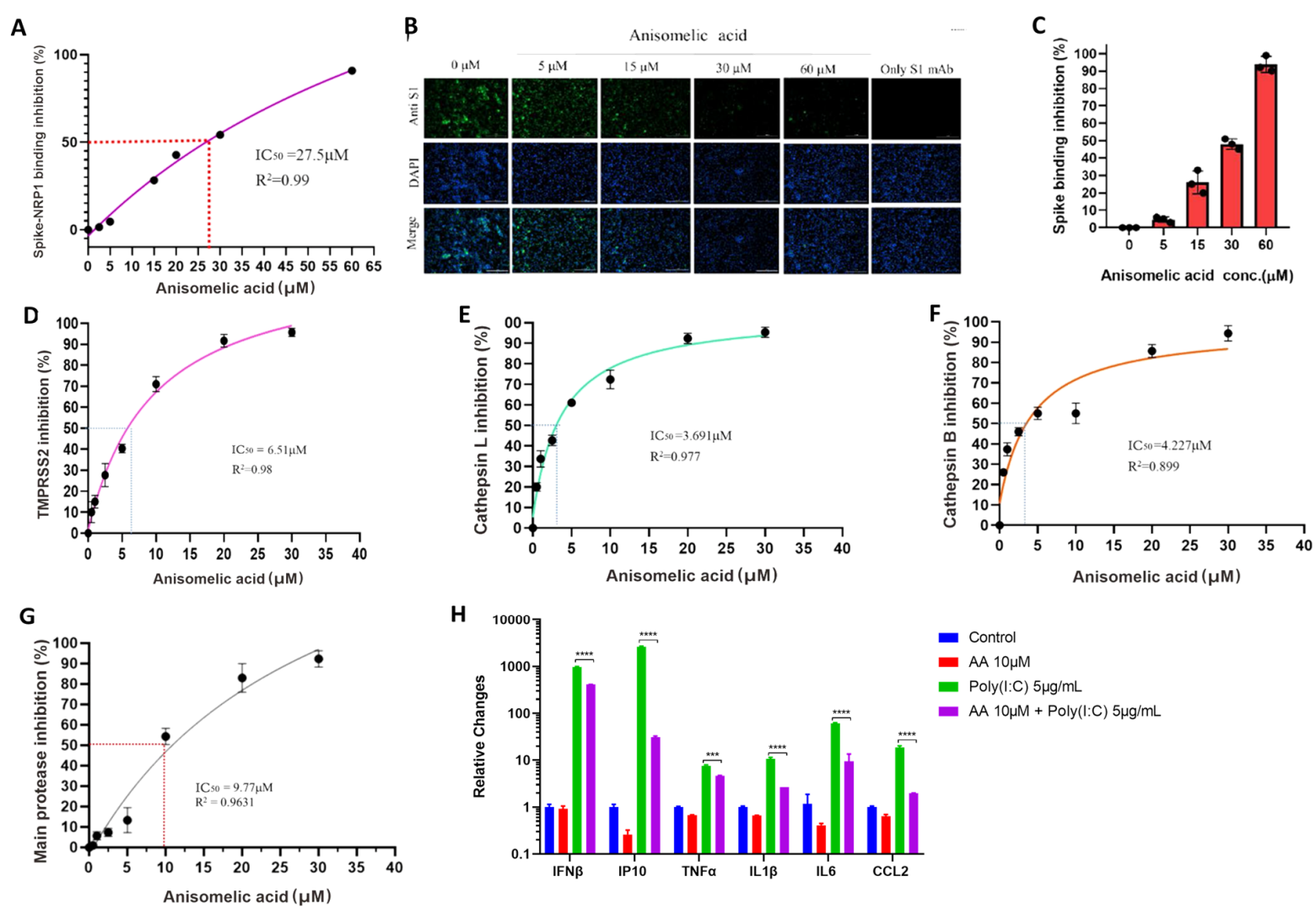

Figure 3. (-)-Anisomelic acid inhibition of multiple targets in the viral infection cycle. (A-C) (-)-Anisomelic acid gave dosedependent inhibition of binding of viral spike protein with neuropilin-1 and NRP1-positive Huh7 cell line. (D-F) (-)-Anisomelic acid inhibited the activity of TMPRSS2 (D), cathepsin-L (E), and cathepsin B (F) in a dose-dependent manner. (G) Dose-response curve for main protease inhibition by (-)-anisomelic acid. (H) Inhibition of mRNA expression of inflammatory cytokine of THP1 cell line with Poly(I:C) transfection by (-)-anisomelic acid.

Most of the patients with severe COVID-19 have shown significantly increased serum levels of inflammatory cytokines such as IP10, IL6, and TNF-a, which are closely associated with lung injury and disease severity. This cytokine storm is induced by the recognition of viral double-strand RNA via host pattern recognition receptors such as the RIG-I-like receptors or toll-like receptors (38). To determine whether (-)-anisomelic acid ameliorates cytokines release syndrome, human THP-1 cells were transfected 
with poly (I:C), which is often used to stimulate antiviral signaling pathways. Poly (I:C) transfection significantly induced expression of multiple cytokines, i.e., IFN- $\beta$, IP10, IL-1 $\beta$, TNF $\alpha$, IL-6, and CCL2, whereas (-)-anisomelic acid modestly inhibited IFN- $\beta$ expression and significantly suppressed the expression of IP10, IL-1 $\beta$, TNF $\alpha$, IL-6, and CCL2, which are the hallmark cytokines of severe COVID-19 (Fig. 3H). These results suggest that (-)-anisomelic acid not only directly blocks SARS-CoV-2 infection, but also potentially attenuates the excessive host immune response that induces the cytokines release syndrome.

Lastly, we evaluated the effect of (-)-anisomelic acid on SARS-Cov-2 infection in vivo. As shown in Fig. 4A, K18-hACE2 mice were infected with SARS-CoV-2 intranasally at day 0 after administration of the first treatment dose (vehicle, remdesivir $25 \mathrm{mg} / \mathrm{kg}$ bid S.C., (-)-anisomelic acid 35 and $70 \mathrm{mg} / \mathrm{kg}$ qd P.O. and (+)-ovatodiolide 35 and $70 \mathrm{mg} / \mathrm{kg}$ qd P.O.). The entire treatment lasted till day 5 . Four hours after administration of the last dose on day 5, the mice were sacrificed and the viral loads in their lung tissues

A

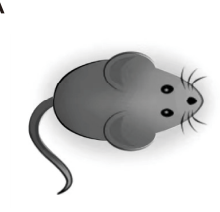

K18 hACE2 mice

B

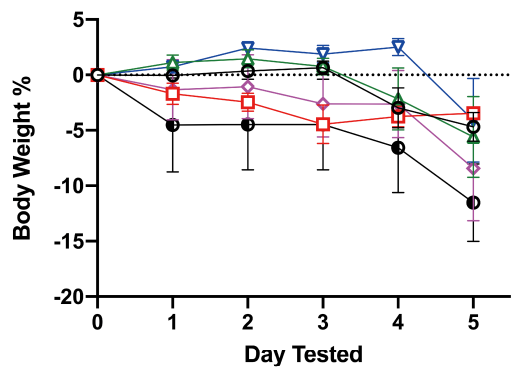

SARS-CoV-2

$$
\text { infection }
$$

Day

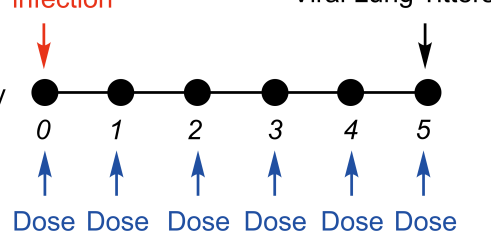

- Vehicle

- - Remdesivir

(25 mg/kg bid, S.C.)

$\triangle$ Ovatodiolide

( $35 \mathrm{mg} / \mathrm{kg}$ qd, P.O.)

$\nabla$ Ovatodiolide

(70 mg/kg qd, P.O.)

$\diamond$ Anisomelic acid

( $35 \mathrm{mg} / \mathrm{kg}$ qd, P.O.)

- Anisomelic acid

(70 mg/kg qd, P.O.)
C

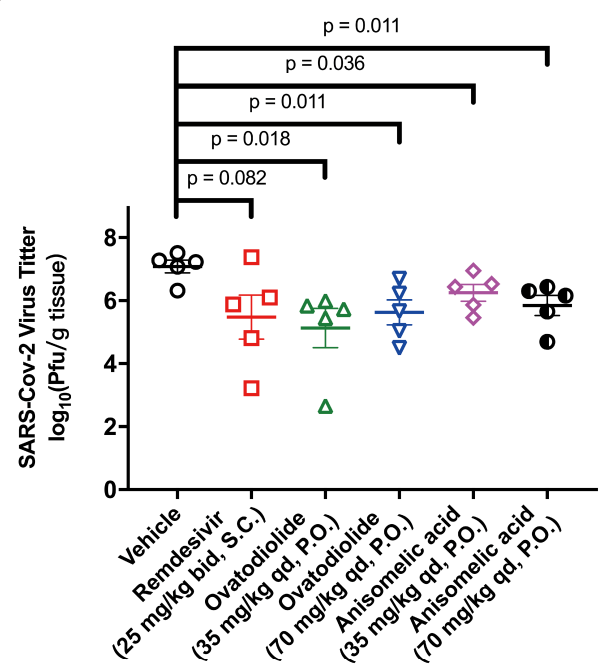

Figure 4. Reduction by (-)-anisomelic acid and (+)-ovatodiolide of SARS-CoV-2 infection in transgenic mice expressing human ACE2 in vivo. (A) Overview of in vivo study design. Mice were dosed at day 0 with vehicle, remdesivir ( $25 \mathrm{mg} / \mathrm{kg}, \mathrm{bid}$, S.C.), (+)-ovatodiolide (35 or $70 \mathrm{mg} / \mathrm{kg}$, qd. P.O.), or (-)-anisomelic acid (35 or $70 \mathrm{mg} / \mathrm{kg}$, qd, P.O.), treatment continued till day 5. Mice were intranasally infected with SARS-CoV-2 $1 \mathrm{~h}$ after the first dose at day 0 . Mice were sacrificed for analysis $4 \mathrm{~h}$ after administration of the last dose. (B) Daily body weights of mice ( $n=5$ per group). Data are mean \pm SD. (C) Virus loads in lung tissue of SARS-CoV-2-infected hACE2 transgenic mice ( $n=5$ per group) were titrated by using a plaque assay. Data are mean \pm SEM. Two-tailed unpaired Student's $t$-test comparison with the vehicle group.

were determined. Fig. 4B showed no significant difference in body weight loss between the control group (vehicle) and all treated groups, indicating that the acute toxicity might not be a major concern (39) in both 
(-)-anisomelic acid and (+)-ovatodiolide, which was further supported by recent results reported on the toxicity study of (+)-ovatodiolide (40). In terms of their antiviral effect, the viral titers in both (-)-anisomelic acid and $(+)$-ovatodiolide treated groups were lower than that of the control group $(p<0.05)$ (Fig. 4C). Remdesivir also reduced viral titters at the tested dose, albeit not significantly ( $p=0.082)$. Taken together, these results show that both (-)-anisomelic acid and (+)-ovatodiolide effectively inhibit SARS-CoV-2 replication in vivo.

In summary, the rapid global spread of SARS-CoV-2 highlights the urgent need for coronavirus therapeutics. We have shown that (-)-anisomelic acid (1) and (+)-ovatodiolide (2) can inhibit SARS-CoV2 at a similar level to those achieved with remdesivir. Their antiviral effects were determined by replication in CPE assay, and a K18-hACE2 mouse model of SARS-CoV-2 via oral administration. To accelerate future drug development, we have established an enantioselective synthesis of (-)-anisomelic acid (1) via a semisynthesis from naturally enriched (+)-costunolide (5) in five steps; the total yield was $27 \%$. This provides opportunities for large-scale, cost-effective production. Given that Anisomeles herbal species have traditionally been used for the treatment of various plagues in China over hundreds of years, (-)-anisomelic acid (1) could be a promising orally bioavailable lead compound for the development of therapeutics against COVID-19.

\section{References and Notes:}

1. WHO Coronavirus Disease (COVID-19) Dashboard. https://covid19.who.int/ accessed Oct. $2^{\text {nd }}$, 2021.

2. W. T. Harvey, A. M. Carabelli, B. Jackson, R. K. Gupta, E. C. Thomson, E. M. Harrison, C. Ludden, R. Reeve, A. Rambaut, S. J. Peacock, D. L. Robertson, C.-G. U. Consortium, SARS-CoV-2 variants, spike mutations, and immune escape. Nat. Rev. Microbiol. 19, 409-424 (2021).

3. D. L. Hughes, Quest for a Cure: Potential Small-Molecule Treatments for COVID-19, Part 2. Org. Process Res. Dev. 25, 1089-1111 (2021).

4. M. N. Namchuk, Early Returns on Small Molecule Therapeutics for SARS-CoV-2. ACS Infect. Dis. 7, 1298-1302 (2021).

5. First COVID-19 treatment recommended for EU authorization, European Medicines Agency, Jun. $25^{\text {th }}, \quad 2020, \quad$ https://www.ema.europa.eu/en/news/first-covid-19-treatment-recommendedeuauthorisation (accessed Jan. 20 $0^{\text {th }}$, 2021).

6. T. P. Sheahan, A. C. Sims, S. Zhou, R. L. Graham, A. J. Pruijssers, M. L. Agostini, S. R. Leist, A. Schäfer, K. H. Dinnon, L. J. Stevens, J. D. Chappell, X. Lu, T. M. Hughes, A. S. George, C. S. Hill, 
S. A. Montgomery, A. J. Brown, G. R. Bluemling, M. G. Natchus, M. Saindane, A. A. Kolykhalov, G. Painter, J. Harcourt, A. Tamin, N. J. Thornburg, R. Swanstrom, M. R. Denison, R. S. Baric, An orally bioavailable broad-spectrum antiviral inhibits SARS-CoV-2 in human airway epithelial cell cultures and multiple coronaviruses in mice. Sci. Trans. Med. 12, eabb5883 (2020).

7. B. Malone, E. A. Campbell, Molnupiravir: Coding for Catastrophe. Nat. Struct. Mol. Biol. 28, 706708 (2021).

8. T. Rodrigues, D. Reker, P. Schneider, G. Schneider, Counting on Natural Products for Drug Design. Nat. Chem. 8, 531-541 (2016).

9. S.-C. Hsieh, S.-H. Fang, Y. K. Rao, Y.-M. Tzeng, Inhibition of Pro-inflammatory Mediators and Tumor Cell Proliferation by Anisomeles indica Extracts. J. Ethnopharmacol. 118, 65-70 (2008).

10. M. G. Dharmasiri, W. D. Ratnasooriya, M. I. Thabrew, Water Extract of Leaves and Stems of Preflowering but not Flowering Plants of Anisomeles indica Possesses Analgesic and Antihyperalgesic Activities in Rats. Pharm. Biol. 41, 37-44 (2003).

11. C. C. Yang, Y. M. Tzeng, Use of Anisomeles indica (l.) kuntze Extract and Purified Products Thereof against Influenza Virus. Taiwan Patent TWI453026B (2014).

12. Y.-L. Chen, Y.-H. Lan, P.-W. Hsieh, C.-C. Wu, S.-L. Chen, C.-T. Yen, F.-R. Chang, W.-C. Hung, Y.-C. Wu, Bioactive Cembrane Diterpenoids of Anisomeles indica. J. Nat. Prod. 71, 1207-1212 (2008).

13. K. K. Purushothaman, R. R. Bhima, K. Kalyani, Ovatodiolide \& Anisomelic Acid, Two Diterpenoid Lactones from Anisomeles malabarica R. Br. Indian J. Chem. 13, 1357-1358 (1975).

14 T. Takahashi, H. Nemoto, Y. Kanda, J. Tsuji, Y. Fujise, [2,3]-Wittig rearrangement of a 13membered diallylic ether. Six-step synthesis of costunolide. J. Org. Chem. 51, 4315-4316 (1986).

15 J. A. Marshall, B. S. DeHoff, Stereoselective Total Synthesis of the Cembranolide Diterpene Anisomelic Acid. Tetrahedron Lett. 27, 4873-4876 (1986).

16 B. M. Fraga, Natural Sesquiterpenoids. Nat. Prod. Rep. 15, 73-92 (1998).

17 W. J. Zuercher, M. Hashimoto, R. H. Grubbs, Tandem Ring Opening-Ring Closing Metathesis of Cyclic Olefins. J. Am. Chem. Soc. 118, 6634-6640 (1996).

18 W. A. Pryor, D. Giamalva, D. F. Church, Kinetics of Ozonation. 1. Electron-Deficient Alkenes. J. Am. Chem. Soc. 105, 6858-6861 (1983). 
Z. G. Brill, M. L. Condakes, C. P. Ting, T. J. Maimone, Navigating the Chiral Pool in the Total Synthesis of Complex Terpene Natural Products. Chem. Rev. 117, 11753-11795 (2017).

20 G. Etemad-Moghadam, J. Seyden-Penne, Synthese Stereoselective d'esters $\alpha, \beta$-Ethyleniques $\alpha$ Methyles $Z$ ou $E$ par la Reaction de Wittig-Horner a Partir de Phosphonates ou d'oxydes de phosphine. Tetrahedron 40, 5153-5166 (1984).

21 W. C. Still, C. Gennari, Direct Synthesis of Z-unsaturated Esters. A Useful Modification of The Horner-Emmons Olefination. Tetrahedron Lett. 24, 4405-4408 (1983).

C. R. Johnson, B. D. Tait, A Cerium (III) Modification of the Peterson Reaction: Methylenation of Readily Enolizable Carbonyl Compounds, J. Org. Chem. 52, 281-283 (1987).

23 Y. Li, H. Wang, X. Tang, S. Fang, D. Ma, C. Du, Y. Wang, H. Pan, W. Yao, R. Zhang, X. Zou, J. Zheng, L. Xu, M. Farzan, G. Zhong, SARS-CoV-2 and Three Related Coronaviruses Utilize Multiple ACE2 Orthologs and Are Potently Blocked by an Improved ACE2-Ig. J. Virol. 94, e0128320 (2020).

24 Q. Zhang, B. Ju, J. Ge, J. F. Chan, L. Cheng, R. Wang, W. Huang, M. Fang, P. Chen, B. Zhou, S. Song, S. Shan, B. Yan, S. Zhang, X. Ge, J. Yu, J. Zhao, H. Wang, L. Liu, Q. Lv, L. Fu, X. Shi, K. Y. Yuen, L. Liu, Y. Wang, Z. Chen, L. Zhang, X. Wang, Z. Zhang, Potent and Protective IGHV353/3-66 Public Antibodies and Their Shared Escape Mutant on the Spike of SARS-CoV-2. Nat. Commun. 12, 4210 (2021).

25 J. Sun, Z. Zhuang, J. Zheng, K. Li, R. L.-Y. Wong, D. Liu, J. Huang, J. He, A. Zhu, J. Zhao, X. Li, Y. Xi, R. Chen, A. N. Alshukairi, Z. Chen, Z. Zhang, C. Chen, X. Huang, F. Li, X. Lai, D. Chen, L. Wen, J. Zhuo, Y. Zhang, Y. Wang, S. Huang, J. Dai, Y. Shi, K. Zheng, M. R. Leidinger, J. Chen, Y. Li, N. Zhong, D. K. Meyerholz, P. B. McCray, Jr., S. Perlman, J. Zhao, Generation of a Broadly Useful Model for COVID-19 Pathogenesis, Vaccination, and Treatment. Cell 182, 734-743 (2020).

26 N. Drayman, J. K. DeMarco, K. A. Jones, S.-A. Azizi, H. M. Froggatt, K. Tan, N. I. Maltseva, S. Chen, V. Nicolaescu, S. Dvorkin, K. Furlong, R. S. Kathayat, M. R. Firpo, V. Mastrodomenico, E. A. Bruce, M. M. Schmidt, R. Jedrzejczak, M. Á. Muñoz-Alía, B. Schuster,V. Nair, K.-V. Han, A. O’Brien, A. Tomatsidou, B. Meyer, M. Vignuzzi, D. Missiakas, J. W. Botten, C. B. Brooke, H. Lee, S. C. Baker, B. C. Mounce, N. S. Heaton, W. E. Severson, K. E. Palmer, B. C. Dickinson, A. Joachimiak, G. Randall, S. Tay, Masitinib is a Broad Coronavirus 3CL Inhibitor that Blocks Replication of SARS-CoV-2. Science 373, 931-936 (2021). 
27 J. Shang, Y. Wan, C. Luo, G. Ye, Q. Geng, A. Auerbach, F. Li, Cell Entry Mechanisms of SARSCoV-2. Proc. Natl. Acad. Sci. U.S.A. 117, 11727-11734 (2020).

28 C. B. Jackson, M. Farzan, B. Chen, H. Choe, Mechanisms of SARS-CoV-2 Entry into Cells. Nat. Rev. Mol. Cell. Biol. 23, 3-20 (2022).

29 L. Cantuti-Castelvetri, R. Ojha, L. D. Pedro, M. Djannatian, J. Franz, S. Kuivanen, F. van der Meer, K. Kallio, T. Kaya, M. Anastasina, T. Smura, L. Levanov, L. Szirovicza, A. Tobi, H. Kallio-Kokko, P. Österlund, M. Joensuu, F. A. Meunier, S. J. Butcher, M. S. Winkler, B. Mollenhauer, A. Helenius, O. Gokce, T. Teesalu, J. Hepojoki, O. Vapalahti, C. Stadelmann, G. Balistreri, M. Simons, Neuropilin-1 Facilitates SARS-Cov-2 Cell Entry and Infectivity. Science 370, 856-860 (2020).

30 J. L. Daly, B. Simonetti, K. Klein, K.-E. Chen, M. K. Williamson, C. Antón-Plágaro, D. K. Shoemark, L. Simón-Gracia, M. Bauer, R. Hollandi, U. F. Greber, P. Horvath, R. B. Sessions, A. Helenius, J. A. Hiscox, T. Teesalu, D. A. Matthews, A. D. Davidson, B. M. Collins, P. J. Cullen, Y. Yamauchi, Neuropilin-1 is a Host Factor for SARS-CoV-2 Infection. Science 370, 861-865 (2020).

31 S. Belouzard, J. K. Millet, B. N. Licitra, G. R. Whittaker, Mechanisms of Coronavirus Cell Entry Mediated by the Viral Spike Protein. Viruses 4, 1011-1033 (2012).

T. Heald-Sargent, T. Gallagher, Ready, Set, Fuse! The Coronavirus Spike Protein and Acquisition of Fusion Competence. Viruses 4, 557-580 (2012).

33 S. Ullrich, C. Nitsche, The SARS-CoV-2 Main Protease as Drug Target. Bioorg. Med. Chem. Lett. 30, 127377 (2020).

34 A. B. Kunnumakkara, D. Bordoloi, G. Padmavathi, J. Monisha, N. K. Roy, S. Prasad, B. B. Aggarwal, Curcumin, the Golden Nutraceutical: Multitargeting for Multiple Chronic Diseases. Br. J. Pharmacol. 174, 1325-1348 (2017).

35 J. Ren, L. Fu, S. H. Nile, J. Zhang, G. Kai, Salvia miltiorrhiza in Treating Cardiovascular Diseases: A Review on Its Pharmacological and Clinical Applications. Front. Pharmacol. 10, 753 (2019).

36 S. Chaudhuri, J. A. Symons, J. Deval, Innovation And Trends in The Development and Approval Of Antiviral Medicines: 1987-2017 and beyond. Antiviral Res. 155, 76-88 (2018).

37 P. I. Andersen, A. Ianevski, H. Lysvand, A. Vitkauskiene, V. Oksenych, M. Bjørås, K. Telling, I. Lutsar, U. Dumpis, Y. Irie, T. Tenson, A. Kantele, D. E. Kainov, Discovery and Development Of Safe-In-Man Broad-Spectrum Antiviral Agents. Int. J. Infect. Dis. 93, 268-276 (2020).

38 D. Blanco-Melo, B. E. Nilsson-Payant, W.-C. Liu, S. Uhl, D. Hoagland, R. Møller, T. X. Jordan, K. Oishi, M. Panis, D. Sachs, T. T. Wang, R. E. Schwartz, J. K. Lim, R. A. Albrecht, B. R. tenOever, 
Imbalanced Host Response to SARS-CoV-2 Drives Development of COVID-19. Cell 181, 10361045.e1039 (2020).

39. J.-T. Jan, T.-J. R. Cheng, Y.-P. Juang, H.-H. Ma, Y.-T. Wu, W.-B. Yang, C.-W. Cheng, X. Chen, T.-H. Chou, J.-J. Shie, W.-C. Cheng, R.-J. Chein, S.-S. Mao, P.-H. Liang, C. Ma, S.-C. Hung, C.-H. Wong, Identification Of Existing Pharmaceuticals and Herbal Medicines as Inhibitors Of SARSCov-2 Infection. Proc. Natl. Acad. Sci. U.S.A. 118, e2021579118 (2021).

40. J.-C. Chen, Y.-Z. Dai, Y.-M. Tzeng, J.-W. Liao, Genotoxicity and 28-Day Repeated Dose Oral Toxicity Study of Ovatodiolide in Rats. Toxicology Rep. 8, 1783-1791 (2021).

Acknowledgments: We thank Prof. Deyin Guo of Sun Yat-sen University for insightful discussions. Funding: This research is supported by the National Science Foundation of China (Grant Nos. 21772004, 21871012, 21933004, 21632002, 21521003, 22077009), Shenzhen Science and Technology Innovation Program (JCYJ20200109120408264, GXWD20201231165807007-20200811141635001, 2019SHIBS0004). Author contributions: Conceptualization: Zhen Yang and Yew-Min Tzeng; Supervision: Zhen Yang, Yew-Min Tzeng, Linqi Zhang, Jun-Min Quan, and Gui-Zhen Wu; Experimental investigation: Hai-Xin Yu, Nan Zheng, Chi-Tai Yeh, Chien-Ming Lee, Qi Zhang, Wen-lv Zheng, Qing Chang, and Yuan-He Li; Writing original draft: Zhen Yang; Writing - review \& editing: all authors. Competing interests: The authors declare no competing interests. Data and materials availability: Experimental procedures, characterization of new compounds, and all other data supporting the findings are available in the supplementary materials. Refined single-crystal X-ray crystallographic result for the structure of (-)-Anisomelic Acid (1) is available free of charge from the Cambridge Crystallographic Data Centre under deposition number 2116979. 